\title{
Efficacy of indacaterol/glycopyrronium versus salmeterol/fluticasone in current and ex-smokers: a pooled analysis of IGNITE trials
}

\author{
David M.G. Halpin ${ }^{1}$, Claus F. Vogelmeier ${ }^{2}$, Karen Mezzi ${ }^{3}$, Pritam Gupta ${ }^{4}$, \\ Konstantinos Kostikas $\mathbb{1 0}^{5}$ and Jadwiga A. Wedzicha ${ }^{6}$
}

Affiliations: 'University of Exeter Medical School, College of Medicine and Health, University of Exeter, Exeter, UK. ${ }^{2}$ University Medical Centre Giessen and Marburg, member of the German Centre for Lung Research (DZL), Marburg, Germany. ${ }^{3}$ Novartis Pharma AG, Basel, Switzerland. ${ }^{4}$ Novartis Healthcare Pvt. Ltd., Hyderabad, India. ${ }^{5}$ Respiratory Medicine Dept, University of Ioannina, loannina, Greece. ${ }^{6}$ National Heart and Lung Institute, Imperial College London, London, UK.

Correspondence: David M.G. Halpin, University of Exeter Medical School, College of Medicine and Health, University of Exeter, Exeter, UK. E-mail: d.halpinanhs.net

ABSTRACT Inhaled corticosteroids have proven to be less effective in asthmatic patients who smoke; however, there is limited information on the efficacy of inhaled corticosteroid-containing regimens in COPD patients who continue smoking. We evaluate the differential efficacy of once-daily indacaterol/glycopyrronium $110 / 50 \mu \mathrm{g}$ compared with twice-daily salmeterol/fluticasone 50/500 $\mu \mathrm{g}$ in current smokers and ex-smokers with COPD.

A pooled analysis of data from ILLUMINATE, LANTERN and FLAME studies was conducted to assess the efficacy of indacaterol/glycopyrronium compared with salmeterol/fluticasone in current smokers and exsmokers with COPD. Efficacy was assessed in terms of improvements in trough forced expiratory volume in $1 \mathrm{~s}\left(\mathrm{FEV}_{1}\right)$, transition dyspnoea index (TDI) focal score, St George's Respiratory Questionnaire (SGRQ) total score, reduced rescue medication use and exacerbation prevention at 26 weeks after the start of the therapy.

In total, 1769 (38\%) current smokers and 2848 (62\%) ex-smokers were included. Patients treated with indacaterol/glycopyrronium experienced greater improvements in trough $\mathrm{FEV}_{1}$ versus salmeterol/ fluticasone in both current and ex-smokers (least squares mean treatment difference, $105 \mathrm{~mL}$ and $78 \mathrm{~mL}$, respectively). Improvements in TDI focal score, SGRQ total score and reduction in rescue medication use were also greater with indacaterol/glycopyrronium versus salmeterol/fluticasone in current and ex-smokers. Furthermore, indacaterol/glycopyrronium reduced all exacerbations (moderate/severe) compared with salmeterol/fluticasone, irrespective of smoking status. The difference in efficacy in favour of indacaterol/ glycopyrronium was more prominent in current smokers in most cases.

Indacaterol/glycopyrronium demonstrated greater efficacy versus salmeterol/fluticasone, and the differences were generally more prominent in current smokers suggesting smoking may reduce the effects of salmeterol/fluticasone.

@ERSpublications

In both current smokers and ex-smokers with COPD, indacaterol/glycopyrronium demonstrates greater efficacy than salmeterol/fluticasone but the difference is more prominent in current smokers for most of the evaluated parameters https://bit.ly/2Ih8Hq3

Cite this article as: Halpin DMG, Vogelmeier CF, Mezzi K, et al. Efficacy of indacaterol/ glycopyrronium versus salmeterol/fluticasone in current and ex-smokers: a pooled analysis of IGNITE trials. ERJ Open Res 2021; 7: 00816-2020 [https://doi.org/10.1183/23120541.00816-2020].

This article has supplementary material available from openres.ersjournals.com

The IGNITE trials are registered at www.clinicaltrials.gov with identifier numbers NCT01315249, NCT01709903 and NCT01782326. Novartis is committed to sharing access to patient-level data and supporting documents from eligible studies with qualified external researchers. These requests are reviewed and approved by an independent review panel based on scientific merit. All data provided are anonymised to respect the privacy of patients who have participated in the trial in line with applicable laws and regulations.

Received: 2 Nov 2020 | Accepted: 5 Nov 2020

Copyright $\odot$ ERS 2021. This article is open access and distributed under the terms of the Creative Commons Attribution Non-Commercial Licence 4.0. 


\section{Introduction}

Smoking is the leading cause of COPD; in 2005, $\sim 5.4$ million deaths were due to tobacco use. Numbers of tobacco-related deaths are expected to increase to 8.3 million by 2030 [1]. At least $25 \%$ of smokers develop COPD, making smoking a major risk factor $[2,3]$. The prevalence of COPD is considerably higher in smokers and ex-smokers compared with nonsmokers $[4,5]$. Smoking cessation reduces lung function decline and mortality and is the most important management strategy for patients with COPD who are smokers [6-8]. Individuals should be encouraged to quit smoking at every available opportunity. Legislative smoking bans are highly effective in promoting quitting and reducing harm from second-hand smoke exposure [9].

However, despite awareness of the benefits of smoking cessation, a high proportion of the COPD population continue to smoke ( $\sim 20 \%$ of the global COPD population) [2,10-13], which highlights the need for selection of appropriate pharmacological therapy in these patients.

Inhaled long-acting bronchodilators (LABDs) are the mainstay of pharmacological management of COPD $[6,14]$. LABDs, including long-acting $\beta_{2}$-agonists (LABAs) and long-acting muscarinic antagonists (LAMAs), improve lung function and health-related quality of life, and reduce rescue medication use and exacerbations in patients with COPD [15].

Use of inhaled corticosteroids (ICS) in combination with a LABA, or as triple therapy with a LABA and LAMA, is proposed to be guided by exacerbation history and patients' eosinophil counts [6]. ICS have proven to be less effective in patients with asthma who are active smokers, showing fewer short-term lung function improvements and reduced anti-inflammatory effects, compared with nonsmokers [16, 17]. Smoking may have similar effects on therapeutic response to ICS in patients with COPD; however, very limited data are available to support this. A post hoc analysis of the SUMMIT trial demonstrated impaired response to ICS-containing therapy for important clinical outcomes in patients with COPD who continued smoking [18].

We conducted a pooled analysis of the ILLUMINATE, LANTERN and FLAME [19-21] trials to evaluate the efficacy of once-daily indacaterol/glycopyrronium 110/50 $\mu$ g (IND/GLY, a LABA/LAMA) versus twice-daily salmeterol/fluticasone 50/500 $\mathrm{g}$ (SFC, a LABA/ICS) in current and ex-smokers with COPD, and to understand whether smoking impairs response to ICS in patients with COPD.

\section{Methods}

\section{Study design}

This is a pooled post hoc analysis of data from the ILLUMINATE (NCT01315249), LANTERN (NCT01709903) and FLAME (NCT01782326) studies. ILLUMINATE and LANTERN were 26-week, multicentre, double-blind, double-dummy, parallel-group studies that randomised (1:1) patients with moderate-to-severe COPD to receive either IND/GLY $110 / 50 \mu \mathrm{g}$ once daily via the Breezhaler ${ }^{\circledast}$ device or SFC $50 / 500 \mu \mathrm{g}$ twice daily via the Accuhaler ${ }^{\circledR}$ device $[19,21]$. FLAME was a 52-week, multicentre, double-blind, double-dummy, parallel-group study that randomised (1:1) patients with moderate-to-very-severe COPD with $\geqslant 1$ exacerbation in the previous year to receive either IND/GLY 110/ $50 \mu \mathrm{g}$ once daily via the Breezhaler ${ }^{\otimes}$ device or SFC 50/500 $\mu \mathrm{g}$ twice daily via the Accuhaler device [20]. Considering the difference in study durations, this pooled analysis included data after 26 weeks of treatment.

All studies were approved by the Independent Ethics Committee or Institutional Review Boards of each participating centre and were conducted in accordance with the International Conference on Harmonisation Guidelines for Good Clinical Practice and the Declaration of Helsinki. All patients provided their informed consent for being included in the studies.

\section{Patients}

This pooled analysis included current and ex-smokers, with a smoking history of at least 10 pack-years (10 pack-years are defined as 20 cigarettes a day for 10 years, or 10 cigarettes a day for 20 years, etc.) from ILLUMINATE, LANTERN and FLAME studies.

An ex-smoker was defined as a person who had not smoked for $\geqslant 6$ months at screening. Smoking status was determined as at baseline.

Key inclusion and exclusion criteria of these studies are presented in table S1. Detailed study methodology and patient criteria were reported previously [19-21].

\section{Assessments}

This pooled analysis compared the efficacy of IND/GLY $110 / 50 \mu \mathrm{g}$ once daily versus SFC 50/500 $\mu \mathrm{g}$ twice daily in current and ex-smokers after Week 26 in terms of efficacy end-points common to all studies. Lung function was assessed by improvement in pre-dose trough forced expiratory volume in $1 \mathrm{~s}\left(\mathrm{FEV}_{1}\right)$ 
and proportion of patients achieving minimal clinically important difference (MCID) of $\geqslant 100 \mathrm{~mL}$ increase in trough $\mathrm{FEV}_{1}$ at Week 26 [22]. Dyspnoea was assessed by improvement in transition dyspnoea index (TDI) focal score and proportion of patients achieving MCID of $\geqslant 1$-point increase in the score at Week 26 [23]. Health status was assessed by improvement in the St George's Respiratory Questionnaire (SGRQ) total score and proportion of patients achieving MCID of $\geqslant 4$-point reduction in the score at Week 26 [24]. The change from baseline in rescue medication use (number of puffs per day) over 26 weeks and the annualised rate of all (mild/moderate/severe), moderate/severe and severe exacerbations were also assessed.

\section{Statistical analysis}

All analyses were performed in the full analysis set, which consisted of all patients in the randomised set who received at least one dose of study medication. Patients included in this analysis were smokers or ex-smokers, as assessed at baseline. The changes from baseline in FEV $_{1}$, TDI and SGRQ at Week 26 were analysed using a mixed model for repeated measure (MMRM). The response variables considered were the change in pre-dose trough $\mathrm{FEV}_{1}$, change in TDI score and change in SGRQ score from baseline to Week 26, respectively, for each separate MMRM model. The explanatory variables considered were treatment, baseline value of the parameter of interest ( $\mathrm{FEV}_{1}$, TDI or SGRQ as appropriate), airflow limitation severity, smoking status at baseline, ICS use at screening, region, visit, study and interaction terms between smoking status, treatment, baseline value of the parameter under consideration and visit. The proportion of patients who achieved MCID in terms of $\mathrm{FEV}_{1}$, TDI and SGRQ were analysed using logistic regression. The model included fixed effects for treatment, baseline $\mathrm{FEV}_{1}$, baseline ICS, smoking status, COPD exacerbation history, study, region and interaction term for treatment and smoking status, along with a random effect of centre nested within region. A linear mixed model was considered to analyse the change from baseline in mean daily number of puffs of rescue medication over 26 weeks, with fixed effects of treatment, smoking status at baseline, ICS use at screening, airflow limitation severity, region, study, covariate as baseline mean number of puffs of rescue medication, interaction term between treatment and smoking status at baseline, and random effect of centre nested within region. The rate of annualised COPD exacerbations during 26 weeks of treatment was analysed using a generalised linear model assuming a negative binomial distribution. The time at risk for a patient defined as the exposure time and the log of exposure time in years was used as the offset variable in the model. The explanatory variables considered were: treatment, baseline total symptom score, baseline COPD exacerbation history (i.e. number of COPD exacerbations during the 12 months prior to study), smoking status at baseline, ICS use at screening, region and interaction term between treatment and smoking status.

\section{Results}

\section{Patients}

In total, 4617 patients (ILLUMINATE, 522; LANTERN, 741; FLAME, 3354) were included in this pooled analysis [19-21]. Of these, 1769 (38\%) patients were current smokers and 2848 (62\%) were ex-smokers. The majority of patients were men with a mean age of $\geqslant 60$ years in current smokers and ex-smokers. Detailed baseline demographics and clinical characteristics are summarised in table 1.

\section{Lung function}

At Week 26, IND/GLY 110/50 $\mu$ g once daily showed greater improvement in pre-dose trough FEV $_{1}$ versus SFC $50 / 500 \mu \mathrm{g}$ twice daily in both current and ex-smokers (least squares mean treatment difference $(\Delta$ ), 105 and $78 \mathrm{~mL}$, respectively; figure 1). In current smokers, improvement in trough $\mathrm{FEV}_{1}$ exceeded the MCID of $\geqslant 100 \mathrm{~mL}$ with IND/GLY $110 / 50 \mu \mathrm{g}$ once daily versus SFC 50/500 $\mu \mathrm{g}$ twice daily.

\section{Dyspnoea and health status}

Both IND/GLY $110 / 50 \mu \mathrm{g}$ once daily and SFC 50/500 $\mu \mathrm{g}$ twice daily demonstrated improvement in TDI focal score from baseline after 26 weeks of treatment. In the current smokers, the improvement in TDI focal score was greater with IND/GLY $110 / 50 \mu \mathrm{g}$ once daily compared with SFC 50/500 $\mu \mathrm{g}$ twice daily, with a difference of 0.85 points at Week 26, in comparison with the ex-smokers, where the difference was merely 0.29 points (figure 2 ).

In current smokers and ex-smokers, improvement in health status (as evident from reduction in the SGRQ total score) was found to be greater with IND/GLY $110 / 50 \mu \mathrm{g}$ once daily compared with SFC 50/500 $\mu \mathrm{g}$ twice daily at Week 26, with a more pronounced difference in current smokers (figure 3 ).

\section{Rescue medication use}

In current smokers and ex-smokers, daily rescue medication use over 26 weeks of treatment was reduced with IND/GLY 110/50 $\mu \mathrm{g}$ once daily compared with SFC 50/500 $\mu \mathrm{g}$ twice daily; with greater reduction in use of rescue medication observed in current smokers (figure 4). 


\begin{tabular}{|c|c|c|c|c|}
\hline \multirow[t]{2}{*}{ Characteristic } & \multicolumn{2}{|c|}{ Current smoker $\#$} & \multicolumn{2}{|c|}{ Ex-smoker ${ }^{\Uparrow}$} \\
\hline & $\begin{array}{l}\text { IND/GLY } \\
110 / 50 \mu g \\
\text { once daily }\end{array}$ & $\begin{array}{c}\text { SFC } \\
50 / 500 \mu g \\
\text { twice daily }\end{array}$ & $\begin{array}{l}\text { IND/GLY } \\
110 / 50 \mu g \\
\text { once daily }\end{array}$ & $\begin{array}{c}\text { SFC } \\
50 / 500 \mu g \\
\text { twice daily }\end{array}$ \\
\hline Subjects $\mathbf{n}$ & 879 & 890 & 1427 & 1421 \\
\hline Age years & $62.1 \pm 7.51$ & $62.0 \pm 7.07$ & $66.0 \pm 7.80$ & $66.0 \pm 7.76$ \\
\hline Male & $643(73.2)$ & $638(71.7)$ & 1175 (82.3) & $1136(79.9)$ \\
\hline $\mathrm{BMI} \mathbf{k g} \cdot \mathrm{m}^{-2}$ & $25.0 \pm 5.00$ & $25.1 \pm 5.24$ & $26.0 \pm 5.07$ & $26.1 \pm 4.95$ \\
\hline Estimated number of pack-years & $43.0 \pm 18.51$ & $44.4 \pm 21.88$ & $39.6 \pm 22.58$ & $39.3 \pm 22.00$ \\
\hline Duration of COPD years & $6.0 \pm 4.75$ & $6.3 \pm 5.13$ & $7.2 \pm 5.54$ & $7.4 \pm 5.60$ \\
\hline $\begin{array}{l}\text { Blood eosinophil count at baseline } \\
\text { cells } \mu \mathrm{L}^{-1}\end{array}$ & $205.4 \pm 141.32$ & $205.9 \pm 160.36$ & $209.5 \pm 156.47$ & $207.1 \pm 166.62$ \\
\hline \multicolumn{5}{|c|}{ Severity of airflow limitation, GOLD 2019} \\
\hline Mild, GOLD 1 & $2(0.2)$ & $1(0.1)$ & & \\
\hline Moderate, GOLD 2 & $386(43.8)$ & $397(44.6)$ & $573(40.2)$ & 573 (40.3) \\
\hline Severe, GOLD 3 & $437(49.6)$ & $442(49.6)$ & 761 (53.3) & 758 (53.3) \\
\hline Very severe, GOLD 4 & $47(5.3)$ & $44(4.9)$ & $85(6.0)$ & $80(5.6)$ \\
\hline Missing & $9(1.0)$ & $7(0.8)$ & $8(0.6)$ & $11(0.8)$ \\
\hline \multicolumn{5}{|l|}{ Treatments at baseline ${ }^{+}$} \\
\hline LABA & $430(48.8)$ & 453 (50.8) & 698 (48.9) & $674(47.5)$ \\
\hline LAMA & $393(44.6)$ & $415(46.6)$ & $613(43.0)$ & $612(43.0)$ \\
\hline ICS & $442(50.2)$ & 448 (50.3) & $826(57.9)$ & $802(56.4)$ \\
\hline LABA/ICS & $283(32.1)$ & 295 (33.1) & $501(35.1)$ & $483(34.0)$ \\
\hline \multicolumn{5}{|l|}{ COPD exacerbation history } \\
\hline 0 & 209 (23.7) & $200(22.4)$ & $361(25.3)$ & $340(23.9)$ \\
\hline 1 & 549 (62.3) & 570 (64.0) & $863(60.5)$ & $878(61.7)$ \\
\hline$\geqslant 2$ & $123(14.0)$ & $120(13.5)$ & 203 (14.2) & 204 (14.3) \\
\hline
\end{tabular}

Data are presented as mean \pm SD or $n(\%)$, unless otherwise stated. IND/GLY: indacaterol/glycopyrronium; SFC: salmeterol/fluticasone; BMI: body mass index; GOLD: Global Initiative for Chronic Obstructive Lung Disease; LABA: long-acting $\beta_{2}$-agonist; LAMA: long-acting muscarinic antagonist; ICS: inhaled corticosteroid. " : $\mathrm{N}=1769 ;{ }^{\text {ๆ }}$ : $\mathrm{N}=2848 ;{ }^{+}$: patients might be on more than one COPD therapy at baseline.

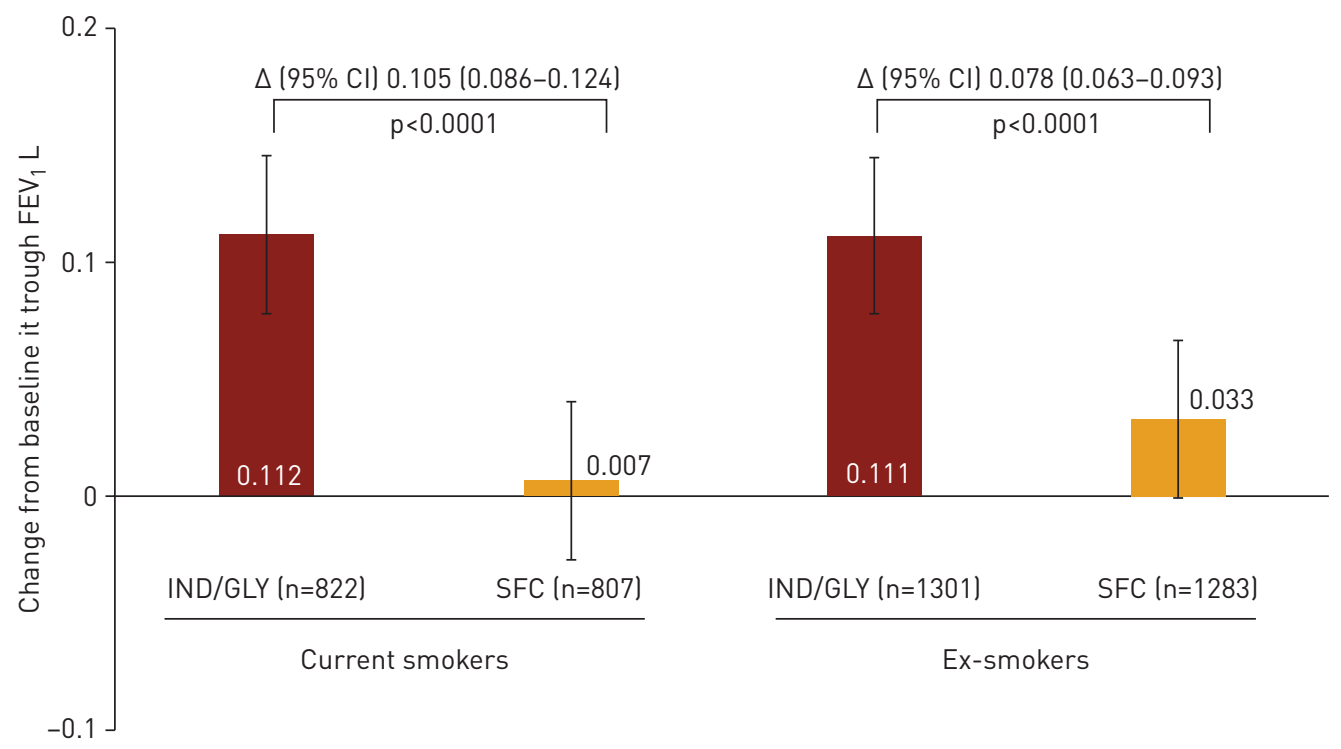

FIGURE 1 Treatment difference with indacaterol/glycopyrronium 110/50 $\mu$ g once daily (IND/GLY) versus salmeterol/fluticasone $50 / 500 \mu \mathrm{g}$ twice daily (SFC) in current and ex-smokers for pre-dose trough forced expiratory volume in $1 \mathrm{~s}\left(\mathrm{FEV}_{1}\right)$ after 26 weeks of treatment (full analysis set). Data are presented as least

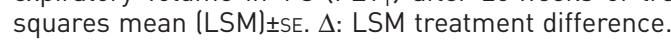




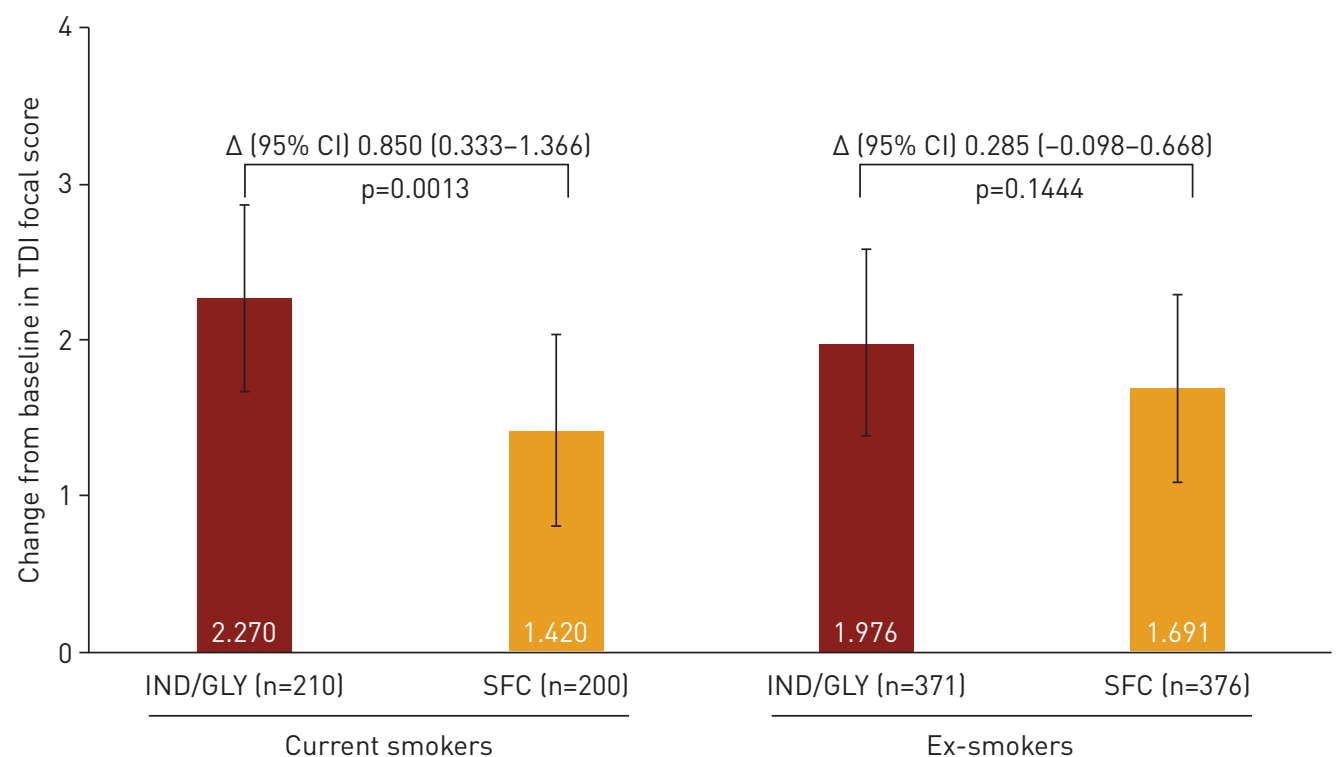

FIGURE 2 Treatment difference with indacaterol/glycopyrronium 110/50 $\mu \mathrm{g}$ once daily (IND/GLY) versus salmeterol/fluticasone $50 / 500 \mu \mathrm{g}$ twice daily (SFC) in current and ex-smokers for transition dyspnoea index (TDI) focal score after 26 weeks of treatment (full analysis set). Data are presented as least squares mean $($ LSM \pm SE. $\Delta$ : LSM treatment difference.

\section{Responder analysis}

Regardless of smoking status, the proportion of patients achieving MCID of $\geqslant 100 \mathrm{~mL}$ improvement in trough $\mathrm{FEV}_{1}$ was higher with IND/GLY $110 / 50 \mu \mathrm{g}$ once daily than SFC 50/500 $\mu \mathrm{g}$ twice daily at Week 26 (figure 5). The percentage of patients achieving MCID in trough $\mathrm{FEV}_{1}$ with IND/GLY 110/50 $\mu$ g once daily was slightly higher among smokers than ex-smokers. In current smokers, the proportion of patients achieving clinically meaningful improvement in TDI focal score (MCID of $\geqslant 1$ point) was numerically greater with IND/GLY 110/50 $\mu$ g once daily compared with SFC 50/500 $\mu$ g twice daily at Week 26, while it

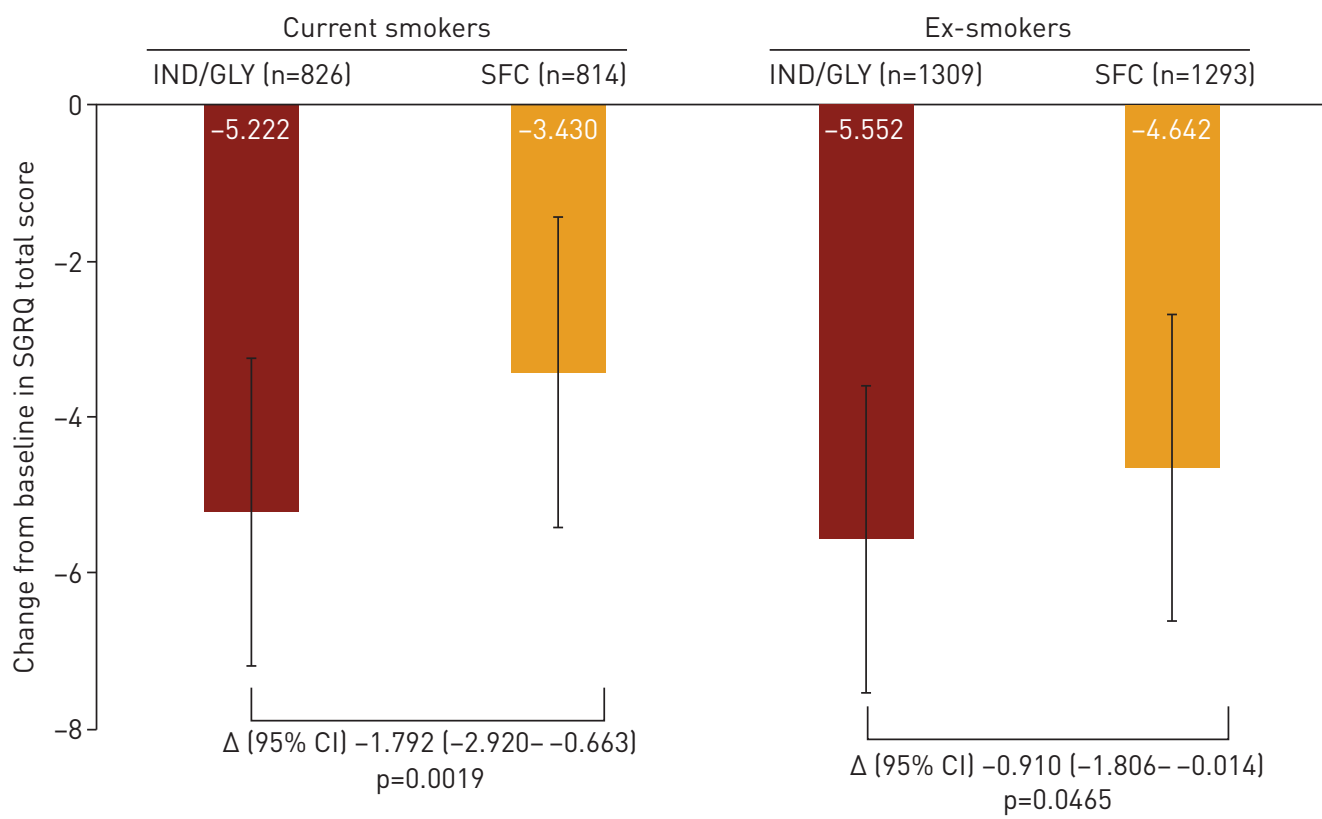

FIGURE 3 Treatment difference with indacaterol/glycopyrronium 110/50 $\mu$ g once daily (IND/GLY) versus salmeterol/fluticasone $50 / 500 \mu \mathrm{g}$ twice daily (SFC) in current and ex-smokers for St George's Respiratory Questionnaire (SGRQ) total score after 26 weeks of treatment (full analysis set). Data are presented as least squares mean (LSM) \pm SE. $\Delta$ : LSM treatment difference. 


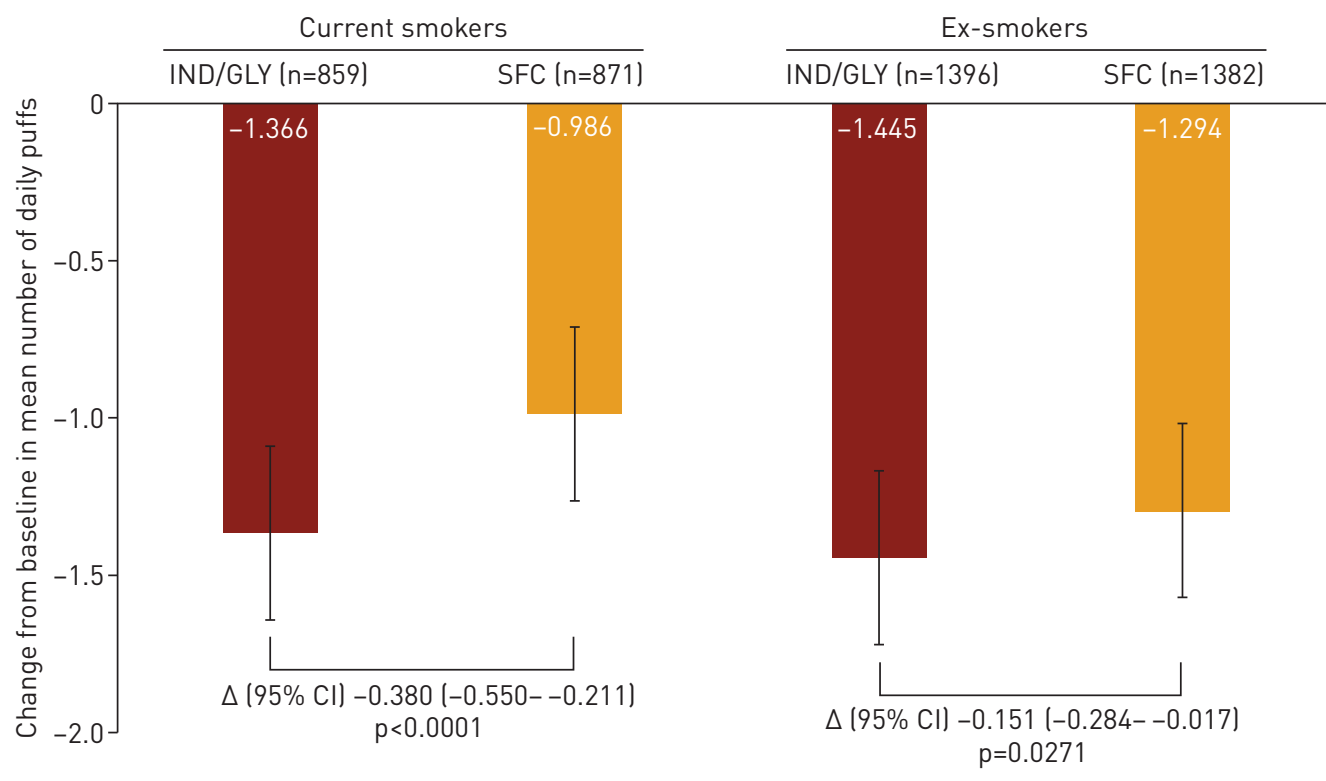

FIGURE 4 Treatment difference with indacaterol/glycopyrronium 110/50 $\mu \mathrm{g}$ once daily (IND/GLY) versus salmeterol/fluticasone $50 / 500 \mu \mathrm{g}$ twice daily (SFC) in current and ex-smokers in rescue medication use after 26 weeks of treatment (full analysis set). Data are presented as least squares mean (LSM) \pm SE. $\Delta$ : LSM treatment difference.

did not differ between the two treatments in ex-smokers (figure 5). The proportion of patients with a $\geqslant 4$-unit reduction in the SGRQ total score (MCID) at Week 26 was higher with IND/GLY 110/50 $\mu$ g once daily than SFC 50/500 $\mu \mathrm{g}$ twice daily, regardless of the smoking status (figure 5).

\section{Exacerbations}

In both current and ex-smokers, IND/GLY 110/50 $\mu \mathrm{g}$ once daily reduced all types of exacerbation events (all (mild/moderate/severe), moderate/severe or severe) compared with SFC 50/500 $\mu \mathrm{g}$ twice daily at Week 26 (figure 6). In current smokers, exacerbation prevention was more pronounced for all (mild/moderate/ severe) exacerbations and for severe exacerbations.

Patients OR $(95 \% \mathrm{Cl})$ achieving MCID \%

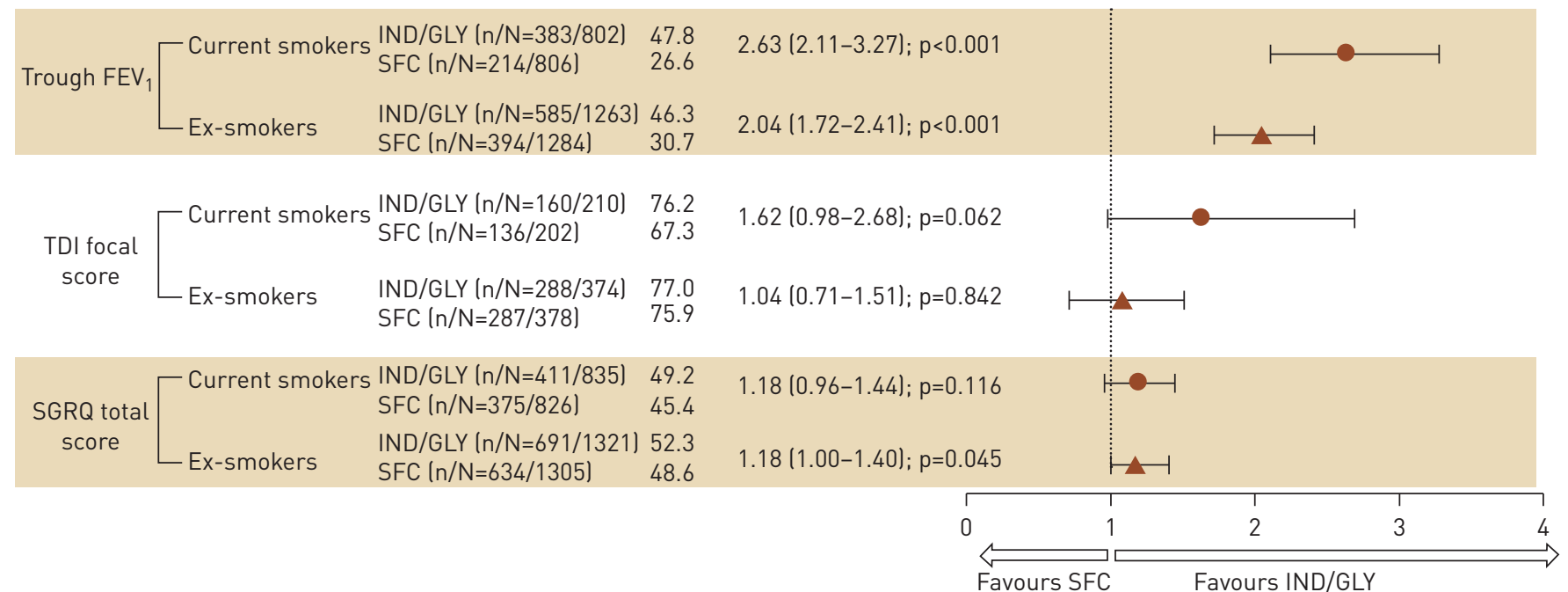

FIGURE 5 Proportion of patients achieving the minimal clinically important difference (MCID) for trough forced expiratory volume in $1 \mathrm{~s}$ (FEV $)_{1}$, St George's Respiratory Questionnaire (SGRQ) total score and transition dyspnoea index (TDI) focal score with indacaterol/glycopyrronium $110 / 50 \mu \mathrm{g}$ once daily (IND/GLY) and salmeterol/fluticasone 50/500 $\mu \mathrm{g}$ twice daily (SFC) after 26 weeks (full analysis set). 
Rate ratio $(95 \% \mathrm{Cl})$

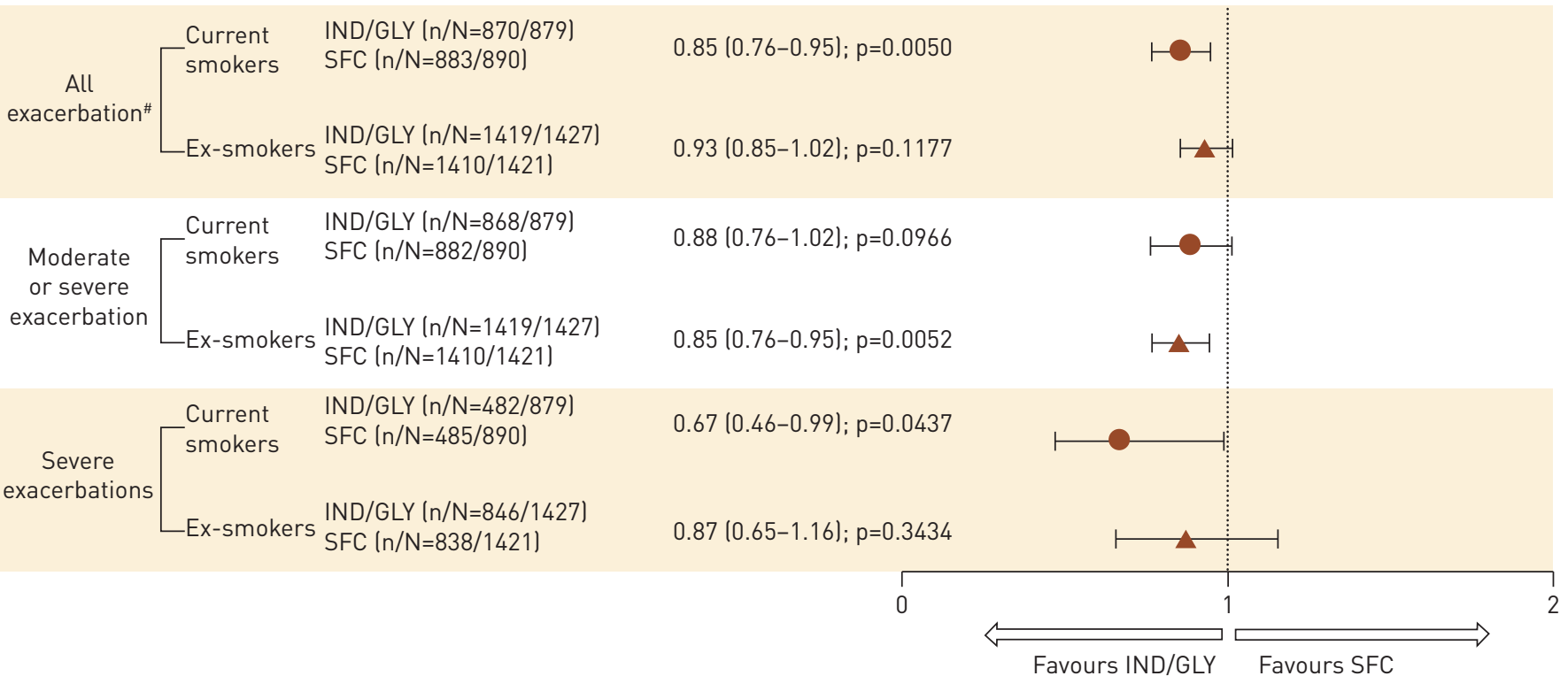

FIGURE 6 Annualised rate of all (mild/moderate/severe), moderate/severe and severe exacerbations after 26 weeks by baseline smoking status (full analysis set). IND/GLY: indacaterol/glycopyrronium 110/50 $\mu \mathrm{g}$ once daily; SFC: salmeterol/fluticasone 50/500 $\mu \mathrm{g}$ twice daily. ${ }^{\#}$ : including mild/ moderate/severe exacerbations.

\section{Discussion}

This post hoc analysis of pooled data from ILLUMINATE, LANTERN and FLAME [19-21] studies compared the efficacy of IND/GLY (LABA/LAMA) versus SFC (LABA/ICS) in current and ex-smokers. To the best of our knowledge, this is the first pooled analysis to evaluate efficacy of a LABA/LAMA versus a LABA/ICS in patients stratified based on their smoking status.

In both current and ex-smokers, IND/GLY improved lung function, dyspnoea and health-related quality of life, and reduced rescue medication use and exacerbations versus SFC. However, a more pronounced efficacy was observed in current versus ex-smokers, suggesting a potential reduced efficacy of ICS in COPD patients who continue to smoke. The improvement in efficacy outcomes with IND/GLY versus SFC observed in this analysis are in line with the results observed in the overall population in the above three studies from the IGNITE trial programme [19-21].

Studies in patients with asthma have shown reduced efficacy of ICS in improving lung function and reduced anti-inflammatory effects in smokers $[16,17]$. However, limited data are available on the efficacy of ICS-containing regimens in patients with COPD who continue smoking compared with ex-smokers, and studies have shown varied results. Results from this post hoc analysis showed that efficacy of SFC was impaired in smokers compared with ex-smokers for lung function, dyspnoea, health-related quality of life, rescue medication use and exacerbations; however, no direct comparison was made between smokers and ex-smokers within the treatment arms. These results show reduced efficacy with ICS in patients with COPD who continue smoking.

A systematic review of studies in patients with COPD revealed reduced efficacy with ICS in terms of lung function and exacerbation rates in current or heavy smokers compared with lighter or ex-smokers [26]. Consistent with our analysis, a post hoc analysis of the SUMMIT trial showed reduced efficacy in current smokers versus former smokers with ICS/LABA (fluticasone furoate/vilanterol (FF/VI)) versus VI in trough $\mathrm{FEV}_{1}$ [18]. Improvement in SGRQ score was similar with FF/VI versus placebo, irrespective of smoking status.

In the IMPACT study, the percentage reduction in the rate of moderate/severe exacerbation was greater with FF/umeclidinium (UMEC)/VI (an ICS/LABA/LAMA) versus UMEC/VI (a LABA/LAMA) in former smokers $(30 \%)$, compared with current smokers (14\%), suggesting a potentially lower efficacy from the addition of ICS on top of a LABA/LAMA in current smokers [27]. Furthermore, in the SUNSET study, which assessed the direct switch from tiotropium (TIO) plus SFC to IND/GLY, the difference in mean change from baseline in post-dose trough $\mathrm{FEV}_{1}$ with IND/GLY versus TIO+SFC was $-0.048 \mathrm{~L}$ in ex-smokers and $0.001 \mathrm{~L}$ in current smokers, implying lower efficacy with the ICS-containing regimen in 
current smokers compared with ex-smokers in improving trough $\mathrm{FEV}_{1}$ [28]. An exception to the described trend is the results from the TRIBUTE study, showing a greater reduction in moderate-to-severe exacerbation with triple therapy versus IND/GLY in current smokers compared with ex-smokers (adjusted rate ratio 0.778 versus 0.895 , respectively) [29]. Lower exacerbation rates in current smokers and ex-smokers and small sample size included in that analysis should be considered while comparing our findings to the results from the TRIBUTE study. Except for the TRIBUTE study, all the above-discussed studies indicate reduced efficacy with ICS in COPD patients who continue smoking, and our data further support this observation.

Smoking cessation remains key to management of COPD [6]. Smoking cessation has been shown to reduce lung function decline and mortality in patients with COPD, and must always be encouraged in patients with COPD who continue smoking. However, smoking cessation rates are low and many patients continue to smoke [30,31], and are treated by pharmacotherapy. The current analysis has certain strengths and limitations. It should be noted that this analysis was performed in a large pool of smokers and ex-smokers $(\mathrm{n}=4617)$ with a wide range of COPD severity and a relatively balanced proportion of current and ex-smokers (38\% versus 62\%, respectively). The post hoc analysis demonstrated efficacy of IND/GLY versus SFC for all the major clinical outcomes of COPD.

A limitation of this evaluation was that this post hoc analysis was not powered for comparison between the treatment groups; prospective studies for efficacy of ICS on top of effective LABDs (preferably a LABA/ LAMA) in current and ex-smokers are required to validate these outcomes.

\section{Conclusions}

In this post hoc pooled analysis, IND/GLY demonstrated greater efficacy versus SFC in terms of lung function, health-related quality of life, dyspnoea, rescue medication use and exacerbation prevention in both current and ex-smokers, with a more pronounced difference in certain parameters in current smokers. This analysis supports the use of LABA/LAMA as a preferred treatment option for the majority of patients with COPD, in both current and ex-smokers, and highlights the importance of selecting appropriate pharmacotherapy in patients with COPD who continue to smoke. The efficacy of ICS in individuals with COPD who continue to smoke needs to be further elucidated in properly designed prospective trials. Smoking cessation remains fundamentally important in the management of COPD patients.

Acknowledgements: Under the direction of authors, Vatsal Vithlani and Hasitha Shilpa Anantaraju (professional medical writers; Novartis) assisted in the preparation of this article in accordance with the third edition of Good Publication Practice guidelines. Medical writing support was funded by study sponsor. A part of this analysis was presented in the European Respiratory Society International Congress in 2018 (Paris, France; 15-19 September).

Conflict of interest: D.M.G. Halpin reports personal fees from AstraZeneca, personal fees and nonfinancial support from Boehringer Ingelheim, personal fees from Chiesi and GlaxoSmithKline, personal fees and nonfinancial support from Novartis, and personal fees from Pfizer, CSL Behring and Sanofi, outside the submitted work. C.F. Vogelmeier reports grants and personal fees from AstraZeneca, Boehringer Ingelheim, Chiesi, GlaxoSmithKline, Grifols, Mundipharma and Novartis, personal fees from Cipla, Berlin Chemie/Menarini, CSL Behring and Teva, and grants from the German Federal Ministry of Education and Research (BMBF) Competence Network Asthma and COPD (ASCONET), Bayer Schering Pharma AG, MSD and Pfizer, outside the submitted work. K. Mezzi has nothing to disclose. P. Gupta is an employee of Novartis Healthcare Pvt. Ltd. K. Kostikas reports grants and personal fees from AstraZeneca, Boehringer Ingelheim, Chiesi, ELPEN, Innovis, Novartis, Menarini and GSK, outside the submitted work; and was an employee of Novartis Pharma AG, Basel during the conduct of this study. J.A. Wedzicha reports grants from GSK, and Johnson and Johnson; other support from Novartis, Boehringer Ingelheim, AstraZeneca and GSK; and grants from GSK, AstraZeneca, Boehringer Ingelheim and Novartis, all outside the submitted work.

Support statement: The studies were funded by Novartis Pharma AG, Basel, Switzerland. Funding information for this article has been deposited with the Crossref Funder Registry.

\section{References}

1 World Health Organization. Chronic respiratory diseases. Causes of COPD. www.who.int/respiratory/copd/causes/ en/. Date last accessed: January 31, 2021.

2 Terzikhan N, Verhamme KMC, Hofman A, et al. Prevalence and incidence of COPD in smokers and non-smokers: the Rotterdam Study. Eur J Epidemiol 2016; 31: 785-792.

3 Lokke A, Lange P, Scharling H, et al. Developing COPD: a 25 year follow up study of the general population. Thorax 2006; 61: 935-939.

4 Halbert RJ, Natoli JL, Gano A, et al. Global burden of COPD: systematic review and meta-analysis. Eur Respir J 2006; 28: 523-532.

5 Marsh S, Aldington S, Shirtcliffe P, et al. Smoking and COPD: what really are the risks? Eur Respir J 2006; 28: 883-884.

6 Global Initiative for Chronic Obstructive Lung Disease. Global Strategy for the Diagnosis, Management, and Prevention of Chronic Obstructive Pulmonary Disease. 2020. http://goldcopd.org/gold-reports/. Date last accessed: January 31, 2021. 
7 Aveyard P, Raw M. Improving smoking cessation approaches at the individual level. Tob Control 2012; 21: 252-257.

8 Au DH, Bryson CL, Chien JW, et al. The effects of smoking cessation on the risk of chronic obstructive pulmonary disease exacerbations. J Gen Intern Med 2009; 24: 457-463.

9 Frazer K, Callinan JE, McHugh J, et al. Legislative smoking bans for reducing harms from secondhand smoke exposure, smoking prevalence and tobacco consumption. Cochrane Database Syst Rev 2016; 2: Cd005992.

10 Silkoff PE, Singh D, FitzGerald JM, et al. Inhaled steroids and active smoking drive chronic obstructive pulmonary disease symptoms and biomarkers to a greater degree than airflow limitation. Biomark Insights 2017; 12: 1177271917730306 .

11 Tamimi A, Serdarevic D, Hanania NA. The effects of cigarette smoke on airway inflammation in asthma and COPD: therapeutic implications. Respir Med 2012; 106: 319-328.

12 Lamprecht B, McBurnie MA, Vollmer WM, et al. COPD in never smokers: results from the population-based burden of obstructive lung disease study. Chest 2011; 139: 752-763.

13 Rabe KF, Wedzicha JA. Controversies in treatment of chronic obstructive pulmonary disease. Lancet 2011; 378 $1038-1047$.

14 Ridolo E, Pellicelli I, Gritti B, et al. Patient-reported outcomes and considerations in the management of COPD: focus on indacaterol/glycopyrronium bromide. Patient Prefer Adherence 2019; 13: 145-150.

15 Qaseem A, Wilt TJ, Weinberger SE, et al. Diagnosis and Management of Stable Chronic Obstructive Pulmonary Disease: A Clinical Practice Guideline Update from the American College of Physicians, American College of Chest Physicians, American Thoracic Society, and European Respiratory Society. Ann Intern Med 2011; 155: 179-191.

16 Roche N, Postma DS, Colice G, et al. Differential effects of inhaled corticosteroids in smokers/ex-smokers and nonsmokers with asthma. Am J Respir Crit Care Med 2015; 191: 960-964.

17 Shimoda T, Obase Y, Kishikawa R, et al. Influence of cigarette smoking on airway inflammation and inhaled corticosteroid treatment in patients with asthma. Allergy Asthma Proc 2016; 37: 50-58.

18 Bhatt SP, Anderson JA, Brook RD, et al. Cigarette smoking and response to inhaled corticosteroids in COPD. Eur Respir J 2018; 51: 1701393.

19 Vogelmeier CF, Bateman ED, Pallante J, et al. Efficacy and safety of once-daily QVA149 compared with twice-daily salmeterol-fluticasone in patients with chronic obstructive pulmonary disease (ILLUMINATE) a randomised, double-blind, parallel group study. Lancet Respir Med 2013; 1: 51-60.

20 Wedzicha JA, Banerji D, Chapman KR, et al. Indacaterol-glycopyrronium versus salmeterol-fluticasone for COPD N Engl J Med 2016; 374: 2222-2234.

21 Zhong N, Wang C, Zhou X, et al. LANTERN: a randomized study of QVA149 versus salmeterol/fluticasone combination in patients with COPD. Int J Chron Obstruct Pulmon Dis 2015; 10: 1015-1026.

22 Donohue JF. Minimal clinically important differences in COPD lung function. COPD 2005; 2: 111-124.

23 Mahler DA, Weinberg DH, Wells CK, et al. The measurement of dyspnoea. Contents, interobserver agreement, and physiologic correlates of two new clinical indexes. Chest 1984; 85: 751-758.

24 Jones PW. St George's Respiratory Questionnaire: MCID. COPD 2005; 2: 75-79.

25 Global Initiative for Chronic Obstructive Lung Disease. Global Strategy for the Diagnosis, Management, and Prevention of Chronic Obstructive Pulmonary Disease, 2019. https:/goldcopd.org/archived-reports/. Date last accessed: January 31, 2021.

26 Sonnex K, Alleemudder H, Knaggs R. Impact of smoking status on the efficacy of inhaled corticosteroids in chronic obstructive pulmonary disease: a systematic review. BMJ Open 2020; 10: e037509.

27 Lipson DA, Barnhart F, Brealey N, et al. Once-daily single-inhaler triple versus dual therapy in patients with COPD. N Engl J Med 2018; 378: 1671-1680.

28 Chapman KR, Hurst JR, Frent SM, et al. Long-term triple therapy de-escalation to indacaterol/glycopyrronium in patients with chronic obstructive pulmonary disease (SUNSET): a randomized, double-blind, triple-dummy clinical trial. Am J Respir Crit Care Med 2018; 198: 329-339.

29 Papi A, Vestbo J, Fabbri L, et al. Extrafine inhaled triple therapy versus dual bronchodilator therapy in chronic obstructive pulmonary disease (TRIBUTE): a double-blind, parallel group, randomised controlled trial. Lancet 2018; 391: 1076-1084.

30 Bhatt SP, Kim Y-I, Harrington KF, et al. Smoking duration alone provides stronger risk estimates of chronic obstructive pulmonary disease than pack-years. Thorax 2018; 73: 414-421.

31 Kohansal R, Martinez-Camblor P, Agusti A, et al. The natural history of chronic airflow obstruction revisited: an analysis of the Framingham offspring cohort. Am J Respir Crit Care Med 2009; 180: 3-10. 